\title{
The relationship between coronary artery severity and insulin resistance in patients with impaired glucose tolerance and metabolic syndrome
}

\author{
Yasser Gaber Metwally ${ }^{1 *}$, Heba Kamal Sedrak ${ }^{2}$ and Inas Fahiem Shaltout ${ }^{2}$
}

\begin{abstract}
Background: The relation between metabolic syndrome (MS) and coronary artery disease (CAD) is multifactorial, and the well-known risk factors can explain only about $25 \%$ of the disease as the relation between insulin resistance (IR) on top of MS and severity of CAD still a subject of debate with conflicting data. Also, IR and glucose intolerance are included in the definition of metabolic syndrome only by some associations. So, the aim of this research was to analyze the the relation between CAD severity (measured by the modified Gensini score) and the different components of the metabolic syndrome including insulin resistance and glucose intolerance.

Results: Out of 70 patients enrolled, $71.4 \%$ represented impaired glucose tolerance group (IGT group; $n=50$ ) and $28.6 \%$ represented normal glucose tolerance group (NGT group; $n=20$ ). The following variables were significantly greater among the IGT group including BMI $(30.19 \pm 2.27$ vs $23.62 \pm 2.92 ; P<0.001)$, waist circumference $(105.09 \pm$ 8.02 vs $92.89 \pm 19.92 ; P<0.001$ ), frequency of hypertension ( $80 \%$ vs $50 \% ; P=0.012)$, $2 \mathrm{~h}$ post prandial glucose $(164$ \pm 30 vs $110 \pm 20 ; P<0.04)$, fasting insulin $(9.2 \pm 1.2$ vs $5.1 \pm 4.3 ; P=0.003), \mathrm{HOMA}-\mathrm{IR}(3.03 \pm 0.12 \%$ vs $1.9 \pm 0.12, P$ $<0.001)$, serum uric acid (4.8 \pm 1.3 vs $5.8 \pm 2.6 ; P=0.03$ ), mean modified Gensini score (22.3 \pm 9.2 vs $15.4 \pm 6.8 ; P<$ 0.001 ), while the mean serum HDL was significantly higher among the NGT group ( $40.8 \pm 10.1$ vs $50.6 \pm 10.2$; $P<$ 0.001). There was a positive correlation between HOMA-IR; hs-CRP; MS-related variables (including waist circumflex; BMI; serum uric acid; HDL; TG);and the modified Gensini score (for HOMA, $r=0.63 ; P<0.001$ ). Several predictors for high scores of modified Gensini were noted in multiple regression analysis; however, out of those several predictors, HOMA-IR was the strongest one $(\mathrm{OR}=4.0,95 \% \mathrm{Cl}=(2.04-7.08)$.

Conclusion: IR is an independent risk factor for CAD severity in patients with IGT and MS. In patients with IR; those with aggressive CAD (or with a positive family history of premature CAD), IGT should be managed aggressively even before any evidence of frank diabetes. IR workup should be recommended among the other standard workup for those patients, if documented, interventions targeted against IR should be considered among the other standard management.
\end{abstract}

Keywords: Severity, Intolerance, Metabolic syndrome, Resistance

\footnotetext{
* Correspondence: yassercardio@gmail.com

${ }^{1}$ The Department of Cardiology, Faculty of Medicine, Zagazig University,

Zagazig, Egypt

Full list of author information is available at the end of the article
}

\section{Springer Open}

(c) The Author(s). 2020 Open Access This article is licensed under a Creative Commons Attribution 4.0 International License, which permits use, sharing, adaptation, distribution and reproduction in any medium or format, as long as you give appropriate credit to the original author(s) and the source, provide a link to the Creative Commons licence, and indicate if changes were made. The images or other third party material in this article are included in the article's Creative Commons licence, unless indicated otherwise in a credit line to the material. If material is not included in the article's Creative Commons licence and your intended use is not permitted by statutory regulation or exceeds the permitted use, you will need to obtain permission directly from the copyright holder. To view a copy of this licence, visit http://creativecommons.org/licenses/by/4.0/. 


\section{Background}

In several studies [1-6] but not all $[7,8]$, IR is a coronary artery disease (CAD) risk factor for men and women.

The potential predictive value of metabolic syndrome (MS) as a risk for atherosclerotic cardiovascular disease, as a whole or as individual components is also a matter of discussion [2, 9, 10], with some studies proving and others disproving this association. The research findings from an American study revealed that, while an aggressive deterioration of coronary atherosclerosis seen in MS, that is because specific risk factors are present instead of purely the presence of the disorder [9]. Although insulin resistance (IR) and glucose intolerance, basically not included in the definition of metabolic syndrome by NACEP ATP III, other organizations as the World Health Organization and the European Group for Study of insulin resistance, have considered them as components of metabolic syndrome [10].

CAD incidence was more than doubled among people with impaired fasting glucose (IFG) groups in relation with normal fasting glucose (NFG) groups. Nevertheless, these people have comparable risks for CAD in the DM group. Also after modification of conventional CAD risk factors such as age, high blood pressure, sex, smoking, LDL-C, and triglyceride, these results have persisted. Konstantinou et al. reported that hyperglycemia is a major factor of angiographic CAD occurrence and intensity particularly in the non-diabetic scope [11]. Several studies suggest that IR has a central role in atherosclerosis [3-6].

We hypothesized that IR on top of MS has a role in CAD severity in patients having IGT and MS. Accordingly, the aim of this research was to analyze the relation between CAD severity (measured by modified Gensini score) and the different components of the metabolic syndrome, including insulin resistance and glucose intolerance.

\section{Methods}

The study was conducted from January 2018 to March 2020. The study included 70 consecutive patients with MS referred with stable angina with positive exercise tests for non-urgent coronary angiography (CAG), after excluding all overt diabetic cases, were recruited in this study. Acute coronary syndrome, previous revascularization (PCI or CABG), chronic kidney disease, patients on steroid therapy, those with fluctuating glucose levels, patients with incomplete clinical information, anemia, comorbid vulvar heart disease were other exclusion criteria. The patient then was subdivided into two groups according to a 2-h post-glucose load glycemic level: IGT group $(n=50)$ and NGT group $(n=20)$. The study complied with the CONSORT 2010 statement [12] and the Declaration of Helsinki, and was permitted by the independent medical ethics committee board of the participating centers. All patients gave informed written consents.

Cases related to angina symptoms which could not be sufficiently clarified by non-invasive tests perform coronary angiography using the traditional Judkins technique. Two qualified intervention cardiologists, both not acquainted with the research area and each other, analyzed the angiogram visually and by quantitative coronary angiography. The severity of the recorded CAD angiographically was calculated with the modified Gensini score [13].

Modified Gensini score is a score ranging from 0 to 32 , by dividing the coronary arteries into eight segments and grading stenosis from 1 to 4 in each, according to luminal diameter reduction.

Gensini score depends on the degree of coronary luminal diameter reduction as well as the importance of the stenosis site.

Coronary luminal narrowing is graded as follows:

One point for $\leq 25 \%$, 2 points for $26-50 \%$ narrowing, 4 points for $51-75 \%$ narrowing, 8 points for $76-90 \%, 16$ points for $91-99 \%$ narrowing, and 32 points for 100\%, i.e., total occlusion.

According to the importance of the involved coronary artery, the initial score is further multiplied by a factor, which is 5 in case of the left main coronary artery, 2.5 for the proximal part of the left anterior descending LAD and/or the left circumflex artery Lcx, 1.5 for the mid-region of LAD, 1 for the distal part of LAD, and 1 for mid-distal region of Lcx or right coronary artery.

The scale was measured according to the sum of segments occluded (1 to 27) and represent score III. Score II is a weighted intensity overview for all parts concerned. The consequence of weights for position and severity is the entire weight of each artery sector; the sum of each section is score I (the modified Gensini index), the position, severity, and magnitude [14]. Significant CAD has been described as $>50 \%$ luminous stenosis of one or more large epicarial coronary arteries or their main branches. Segments of each epicardial coronary artery have been measured as follows $[15,16]$ :

(a.) The left main artery (LM) was measured at its midpoint.

(b.) The left anterior descending artery (LAD) was divided into 3 segments, the proximal LAD (PLAD), was evaluated at its middle point between its origin and the first branch (first septal-1S or diagonal-1D) of PLAD, the mid-LAD (mLAD) was evaluated between $1 \mathrm{~S}$ and 1D; and the distal LAD (dLAD) was evaluated after the diagonal branch of the LAD, apical LAD was evaluated in its distal $1.0 \mathrm{~cm}$ before 
the distal bifurcation, commonly referred to as the "pitch fork," "moustache," or "whole's tail."

(c.) The circumflex $\mathrm{Cx}$, proximal $\mathrm{Cx}$ (PCx) was evaluated at its midpoint between its origin and the first obtuse marginal $(1 \mathrm{M})$, the distal Cx ( $\mathrm{d} C \mathrm{x})$ was evaluated at the origin of the second obtuse marginal branch ( $2 \mathrm{M})$; and lastly the obtuse marginal $(1 \mathrm{M})$ was evaluated at its origin.

(d.) The right coronary artery (RCA) was divided into two segments: The proximal RCA (pRCA) was evaluated $15 \mathrm{~mm}$ from the ostium and the distal RCA ( $d$ RCA) was evaluated at the ostium of the posterior descending artery (PDA). In the coronary artery group, evaluation of artery size was done on the most proximal disease.

The three coronary arteries have been quantitatively measured using the edge detection process. Total proximal coronary diameter (PTCD) was measured and defined as PLAD, PCX, and PRCA total. The total distal segments diameter including dLAD, $\mathrm{d} \mathrm{Cx}$, and d RCA has been measured and described as total distal, coronary diameter (d TCD).

\section{Blood samples and analysis}

After $12 \mathrm{~h}$ of overnight fasting, blood samples were drawn from the patients. The Rouche Diagnostic Modular System Analyzer including plasma glucose concentrations has performed all routine blood tests. Patients were given $75 \mathrm{~g}$ of glucose load by oral route, criteria from the World Health Organization (WHO, Geneva), fasting, and a 2-h post-load plasma glucose concentration, evaluated by chemical-metric immune-test, by enzymatic glucose-oxidase method (Roch product, Ontario, Candra) (DPC-Immunite, 2000, no. 152). The estimate of IR by homeostasis (HOMA-IR) model evaluation is based on the estimated insulin sensitivity based on a mathematical modeling of the concentrations of fasting glucose and insulin [17]. Unlike the euglycemic clamp, the HOMA-IR model is a simple, practical, and economical IR assessment method. HOMA-IR formula: fast insulin level (alternative to $\mathrm{U} / \mathrm{ml}$ ) $\times$ fasting glucose $(\mathrm{mg} / \mathrm{dL}) / 405$.

Subjects whose values exceeded the 75 th percentile (i.e., 2.0) were considered to have IR (HOMA-IR index) [18]. Lipid profiles were also measured [19]; HbA1c, hsCRP, and other routine clinical and laboratory testing were done.

\section{Definitions}

Normal fasting glucose (NFG), impaired fasting glucose (IFG), and DM were defined as fasting glucose level < $100 \mathrm{mg} / \mathrm{dL}, 100-125 \mathrm{mg} / \mathrm{dL}$, and > $126 \mathrm{mg} / \mathrm{dL}$, respectively. IGT is defined as a post glucose loading plasma glycemic level between 140 and $199 \mathrm{mg} / \mathrm{dL}$. BMI was measured by weight $(\mathrm{kg}) /$ height $\left(\mathrm{m}^{2}\right)$. The presence of the MS was identified according to the modified $\mathrm{Na}$ tional Cholesterol Education Program Adult Treatment Panel III (NCEP-ATP III) criteria [20].

Premature CAD family history was considered present when a subject had first-grade relatives with CAD history and sudden cardiac deaths before the age of 55 for men and women aged less than 65.

The primary endpoint was assessing the relation between coronary artery severity as measured by the modified Gensini score and IR as measured by the HOMA-RI index in patients with glucose intolerance and MS.

\section{Statistical analysis}

The qualitative data were expressed in mean \pm SD while discrete variables were expressed in percentage. The differences in continuous variables were checked for statistical significance by $t$ test as appropriate; the differences in the discrete variables were checked for statistical significance by $X^{2}$ test. Multiple regression analysis had been done between the severity of CAD and the variables predicting its occurrence. Also, correlation had been done using a post hoc test. $P$ value $<0.05$ was considered significant. The statistical analysis was performed using SPSS.11 for Windows (SPSS Inc., Chicago, IL, USA).

\section{Results}

Out of 70 patients enrolled, $71.4 \%$ represented IGT group, and $28.6 \%$ represented NGT group. The baseline demographic, clinical, biochemical, and angiographic variables of our study population are shown in Table 1. No statistically significant differences in the frequency of age, gender, smokers, or of the mean total cholesterol, LDL, F glucose, and EF\% were found between the two groups. On the other hand, the following variables were higher among the IGT including BMI (30.19 \pm 2.27 vs $23.62 \pm 2.92 ; P<0.001)$, waist circumference $(105.09+/$ -8.02 vs $92.89 \pm 19.92 ; P<0.001)$, frequency of hypertension (80\% vs $50 \% ; P=0.012), 2 \mathrm{~h}$ pp. glucose $(164 \pm$ 30 vs $110 \pm 20 ; P<0.04)$, fasting insulin $(9.2 \pm 1.2$ vs 5.1 $\pm 4.3 ; P=0.003)$, HOMA-IR $(3.03 \pm 0.12 \%$ vs $1.9 \pm 0.12$, $P<0.001)$ as shown in Fig. 1, S. uric acid $(4.8 \pm 1.3$ vs $5.8 \pm 2.6, P=0.03)$, mean modified Gensini score $(22.3$ \pm 9.2 vs $15.4 \pm 6.8, P=0.003$ ) as shown in Fig. 2 , while the mean serum HDL was significantly higher among the NGT group $(40.8 \pm 10.1$ vs $50.6 \pm 10.2, P<0.001)$. Correlation had been done using a post hoc test (shown in Table 2). There was a positive correlation between HOMA and IR; hs-CRP; metabolic syndrome-related variables (including waist circumflex; BMI; serum uric acid; HDL; TG); and the modified Genseni score (for HOMA, $r=0.63 ; P<0.001)$. 
Table 1 Clinical, metabolic, and angiographic variables

\begin{tabular}{|c|c|c|c|}
\hline & IGT group $(n=50)$ & NGT group $(n=20)$ & $P$ value \\
\hline Age & $62 \pm 10.3$ & $61 \pm 9.2$ & 0.7 \\
\hline Male gender & 27 (54\%) & $11(55 \%)$ & \\
\hline BMI $\left(\mathrm{kg} / \mathrm{m}^{2}\right)$ & $30.19 \pm 2.27$ & $23.62 \pm 2.92$ & $<0.001^{* *}$ \\
\hline Waist circum (cm) & $105.09 \pm 8.02$ & $92.89 \pm 19.92$ & $<0.001^{* *}$ \\
\hline Hypertension & $40(80 \%)$ & $10(50 \%)$ & $0.012^{* *}$ \\
\hline Smoking & $10(36 \%)$ & $7(35 \%)$ & 0.93 \\
\hline F. glucose (mg/dl) & $85 \pm 13$ & $80 \pm 10$ & 0.09 \\
\hline $2 \mathrm{~h} \mathrm{bl.} \mathrm{glucose} \mathrm{(mg/dl)}$ & $164 \pm 30$ & $110 \pm 20$ & $<0.04^{*}$ \\
\hline F. serum insulin $(\mu \mathrm{l} \mathrm{U} / \mathrm{ml})$ & $9.2 \pm 1.2$ & $5.1 \pm 4.3$ & $<0.003^{* *}$ \\
\hline HOMA-IR & $3.03 \pm 0.12$ & $1.9 \pm 0.12$ & $<0.001^{* *}$ \\
\hline TG $(\mathrm{mg} / \mathrm{dl})$ & $179.9 \pm 43$ & $110.4 \pm 53.2$ & $<0.001^{* *}$ \\
\hline $\mathrm{HDL}(\mathrm{mg} / \mathrm{dl})$ & $40.8 \pm 10.1$ & $50.6 \pm 10.2$ & $<0.001^{* *}$ \\
\hline Uric acid (mg/dl) & $4.8 \pm 1.3$ & $5.8 \pm 2.6$ & $0.03^{*}$ \\
\hline Modified Gensini score & $22.3 \pm 9.2$ & $15.4 \pm 6.8$ & $0.003^{* *}$ \\
\hline $\mathrm{EF} \%$ & $54 \pm 5.6$ & $55 \pm 6.1$ & 0.51 \\
\hline Hs-CRP (mg/l) & $2.85 \pm 0.31$ & $2.8 \pm 0.30$ & $<0.001^{* *}$ \\
\hline
\end{tabular}

hs-CRP high sensitivity c-reactive protein, HDL high-density lipoprotein, HOMA-IR homeostasis model, HTN hypertension ${ }^{*} P<0.05=$ significant

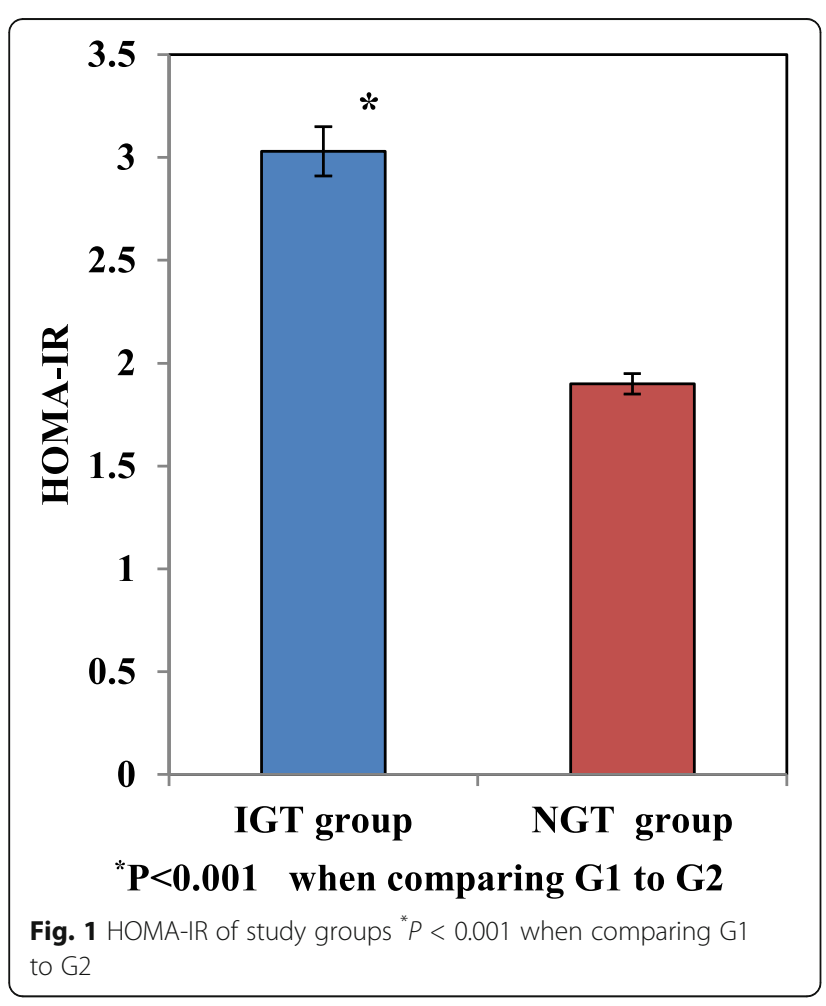

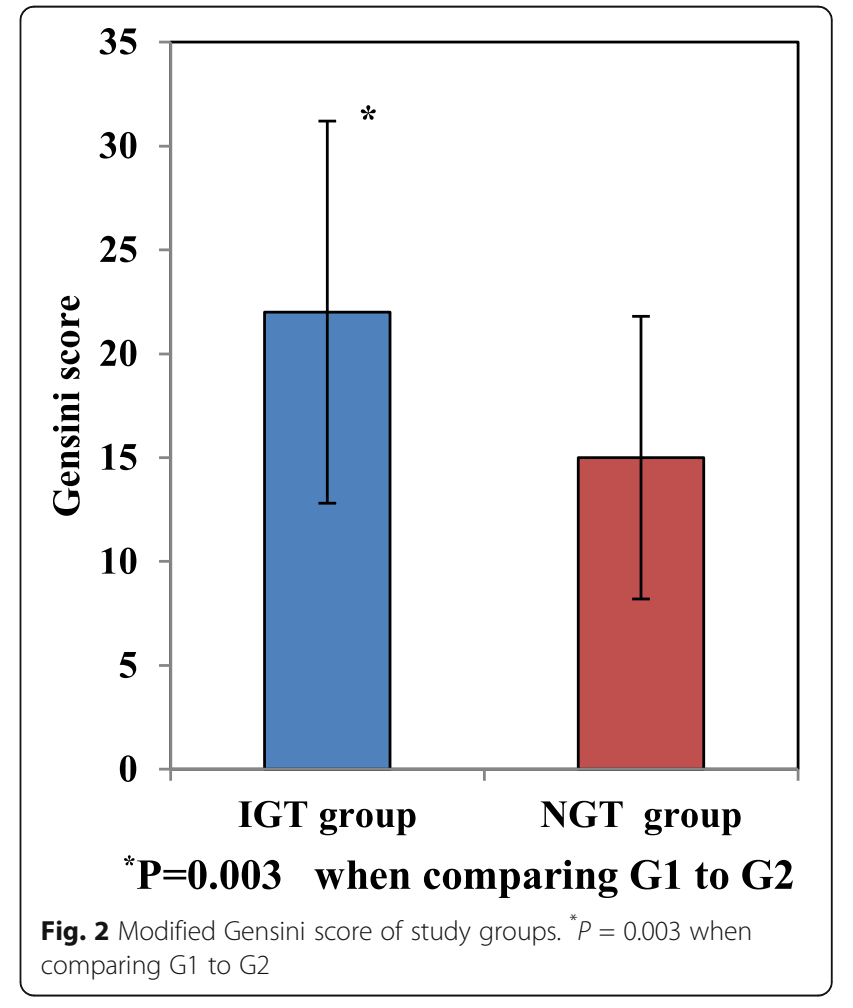


Table 2 Correlation using post hoc test

\begin{tabular}{llll}
\hline & $\boldsymbol{r}$ & $\boldsymbol{P}$ & Significance \\
\hline Age & 0.16 & $>0.05$ & $\mathrm{NS}$ \\
Waist circumference $(\mathrm{cm})$ & 0.55 & $<0.001$ & $\mathrm{HS}$ \\
BMI $(\mathrm{kg} / \mathrm{m} 2)$ & 0.51 & $<0.001$ & $\mathrm{HS}$ \\
Fasting insulin $(\mu \mathrm{lU} / \mathrm{ml})$ & 0.51 & $<0.001$ & $\mathrm{HS}$ \\
Serum uric acid $(\mathrm{mg} / \mathrm{dl})$ & 0.4 & $<0.05$ & $\mathrm{Sig}$. \\
Serum TG $(\mathrm{mg} / \mathrm{dl})$ & 0.59 & $<0.001$ & $\mathrm{HS}$ \\
HDL $(\mathrm{mg} / \mathrm{dl})$ & 0.62 & $<0.001$ & $\mathrm{HS}$ \\
LDL $(\mathrm{mg} / \mathrm{dl})$ & 0.1 & $>0.05$ & $\mathrm{NS}$ \\
hs-CRP $(\mathrm{mg} / \mathrm{l})$ & 0.48 & $<0.05$ & $\mathrm{Sig}$. \\
HOMA-IR & 0.63 & $<0.001$ & $\mathrm{HS}$
\end{tabular}

$B M I$ body mass index, HOMA-IR homeostasis model, $h s-C R P$ high sensitivity Creactive protein, $H D L$ high-density lipoprotein, $L D L$ low-density lipoprotein, NS non-significant

$P<0.05$, significant; $P<0.001$, highly significant

Multiple regression analysis (shown in Table 3) had been done between the severity of CAD (reflected by modified Genseni score) and the variables predicting its occurrence. Several predictors for high modified Genseni scores were noted; however, out of those several predictors, HOMA-IR was the strongest one $(\mathrm{OR}=4.0,95 \%$ $\mathrm{CI}=(2.04-7.08))$.

\section{Discussion}

There have been inconsistent and contradictory reports [2] about the association between insulin resistance and development of major adverse cardiovascular events MACE, including coronary artery disease, with supportive $[3-6,11]$, as well as disproving results $[7,8]$ were discussed above.

Results of our study showed that insulin resistance is the strongest independent risk factor among other components of the metabolic syndrome for severity of CAD in patients with IGT. Several pathophysiological mechanisms have been involved including hyperglycemia per se may be related to atherosclerosis genesis, hyperglycemia can precipitate endothelial barrier injury, impaired endothelial-dependent vasodilation [21], mitochondrial overproduction of reactive oxygen species [22], nuclear factor- $k B$ activation [23], overproduction of adhesive

Table 3 Predictability of CAD severity [modified Gensini score] by different risk factors using multiple regression analysis

\begin{tabular}{lll}
\hline & OR $\mathbf{( 9 5 \% ~ C l )}$ & $P$ value \\
\hline HOMA-IR & $4.0(2.04-7.08)$ & $<0.001^{*}$ \\
HTN & $2.33(1.26-4.35)$ & $0.003^{*}$ \\
hs-CRP $(\mathrm{mg} / \mathrm{l})$ & $1.83(1.01-3.35)$ & $0.033^{*}$ \\
HDL $(\mathrm{mg} / \mathrm{dl})$ & $1.86(1.01-3.41)$ & $0.031^{*}$ \\
\hline
\end{tabular}

hs-CRP high sensitivity C-reactive protein, $H D L$ high-density lipoprotein, $H O M A$ IR homeostasis model, HTN hypertension

${ }^{*} P<0.05=$ significant molecules such as intracellular adhesion molecules (ICAM), vascular cell adhesion molecules (V-CAM), and selectin E [24], as well as continuous exposures to excess glucose of proteins and lipids that cause non-enzymic glycation, and advanced endothelial glycation endproduct synthesis [25] and stimulate superoxide genesis [26]. Both these conditions lead to accelerated atherogenesis and development of atherosclerosis.

We relied more, for our patient group classification, on IGT rather than IFG because the role of IGT is relatively more important in the IR pathophysiology [27].

Previous clinical trials had investigated the relation between IR and CAD severity in patients with IFG and MS.

Health data from the nurses' study indicate that people who are likely to acquire diabetes have three times higher chance of cardiovascular disease $10-15$ years before diabetes starts $[6,28,29]$. This finding was similar to the present study.

American study results have shown that while the aggressive deterioration of the coronary atherosclerosis in MS is noticeable, this is due to various component risk factors rather than the presence of the syndrome itself [9]. Kendall and colleagues [30] reported that IR is the only component of the MS which remains relatively constant throughout the natural history of type 2 diabetes mellitus. Even with conventional treatment, IR, as evaluated by HOMA-IR method, is relatively constant during several years of therapy in the UK prospective diabetes study [31, 32]. Different from the present study, a prospective research in Finland found no significant difference mortality between patients with and without MS, CVD, or CAD in all sample groups through 9 years of follow-up or after multivariable adjustment [33]. In line with current study, Mukund and colleagues [34] reported that coronary artery disease severity could be predicted through IR measuring. Stout reported [35] that hyperinsulinemia documented with oral glucose load is associated with atherosclerotic coronary, cerebral, and peripheral vessels diseases. Zekeriya and colleagues [36] reported that Gensini score in cases of impaired glucose tolerance is greater than cases with normal glucose tolerance. Monteiro et al. [37] reported that male gender and high hs-CRP titer were predictors of severe CAD as assessed by the Genseni score.

\section{Study limitations}

Initially, it is not necessary to extrapolate our sample to the community because our research population was a selectively identified group of CAG patients from cardiology clinics. Secondly, the sample size is small; more numbers of cases may be needed. Thirdly, only CAG has done for assessing atherosclerotic burden. No data about the arterial wall. These patients with a significant 
atherosclerotic burden and preserved lumen (expansive remodeling) will be underestimated and the IVUS study may be more informative. However, as this study was concerned with angiographically severe CAD; thus, CAG may provide the necessary data. Finally, a large portion of our patients were hypertensive and took B blockers and thiazide diuretics known to influence glucose metabolism.

\section{Conclusion}

For patients with IGT and MS, IR is an independent contributing factor for CAD severity. In patients with IR, dangerous CAD increased with positive premature CAD family history, IGT should be managed aggressively even before any evidence of frank diabetes. IR should be recommended among the other routine standard workup for those patients; if documented, interventions targeted against IR should be considered among the other standard management.

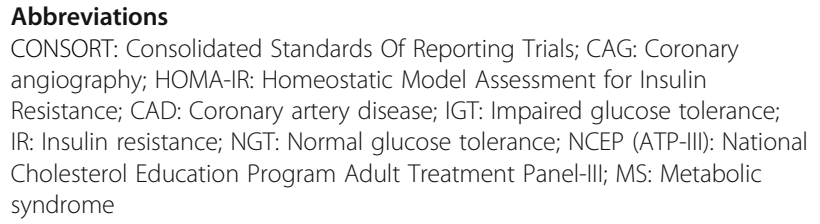

\section{Acknowledgements}

Not applicable

\section{Authors' contributions}

Y.M. had participated in research design, methodology implementation, analysis and data interpreting, writing the original draft, reviewing and finalizing conclusion, project administration. H.S. had participated in literature reviewing, analysis of data, methodology implementation, processing statistics, and reviewing the draft. I.S. had participated in methodology implantation, literature review, data analysis and interpretation, and reviewing the draft. All authors contributed significantly in the research. We certify that all authors have read and approved the final submitted manuscript. We certify that no authors have been removed or added. All authors certified the author list and contribution description; no authors are listed who do not deserve authorship credit and author contribution provided are expressed accurately.

\section{Funding}

All authors declare that no financial or special source of funds.

\section{Availability of data and materials}

All data and materials of the research are available from the corresponding author on reasonable request.

\section{Ethics approval and consent to participate}

An informed written consent had been given from all patients that being was approved by the institutional review board of the Faculty of Medicine, Zagazig University (approval number IRB \# 2920/10-1-2018); the consent was obtained in advance to the study beginning.

\section{Consent for publication}

Not applicable

\section{Competing interests}

All authors declare that they have no competing interests.

\section{Author details}

${ }^{1}$ The Department of Cardiology, Faculty of Medicine, Zagazig University, Zagazig, Egypt. ${ }^{2}$ The Department of Internal Medicine, Faculty of Medicine, Cairo University, Cairo, Egypt.

Received: 30 July 2020 Accepted: 5 October 2020

Published online: 08 December 2020

\section{References}

1. Zornitzki T, Ayzenberg O, Gandelman G, Vered S, Yaskil E, Faraggi D, Knobler $\mathrm{H}$ (2007) Diabetes, but not the metabolic syndrome, predicts the severity and extent of coronary artery disease in women. QJM 100(9):575-581

2. Kahn R, Buse J, Ferrannini E, Stern M (2005) The metabolic syndrome: time for a critical appraisal. Diabetologia. 48(9):1684-1699

3. Després JP, Lamarche $B$, Mauriège $P$, Cantin $B$, Dagenais GR, Moorjani $S$, Lupien PJ (1996) Hyperinsulinemia as an independent risk factor for ischemic heart disease. N Engl J Med 334(15):952-958

4. Pyörälä M, Miettinen H, Laakso M, Pyörälä K (1998) Hyperinsulinemia predicts coronary heart disease risk in healthy middle-aged men: the 22year follow-up results of the Helsinki Policemen Study. Circulation 98(5): 398-404

5. Folsom AR, Szklo M, Stevens J, Liao F, Smith R, Eckfeldt JH (1997) A prospective study of coronary heart disease in relation to fasting insulin, glucose, and diabetes: the Atherosclerosis Risk in Communities (ARIC) Study. Diabetes Care 20(6):935-942

6. Hu FB, Stampfer MJ, Haffner SM, Solomon CG, Willett WC, Manson JE (2002) Elevated risk of cardiovascular disease prior to clinical diagnosis of type 2 diabetes. Diabetes Care 25(7):1129-1134

7. Bressler P, Bailey SR, Matsuda M, DeFronzo RA (1996) Insulin resistance and coronary artery disease. Diabetologia 39(11):1345-1350

8. Welin L, Eriksson H, Larsson B, Ohlson LO, Svärdsudd K, Tibblin G (1992) Hyperinsulinaemia is not a major coronary risk factor in elderly men. Diabetologia 35(8):766-770

9. Bayturan O, Tuzcu EM, Lavoie A, Hu T, Wolski K, Schoenhagen P et al (2010) The metabolic syndrome, its component risk factors, and progression of coronary atherosclerosis. Arch Intern Med 170(5):478-484

10. Eckel RH, Grundy SM (2005) Zimmet PZ. The metabolic syndrome. Lancet 365(9468):1415-1428

11. Konstantinou DM, Chatzizisis YS, Louridas GE, Parcharidis GE, Giannoglou GD (2010) Non-diabetic hyperglycaemia correlates with angiographic coronary artery disease prevalence and severity. Diabetes Metab 36(5):402-408

12. Schulz KF, Altman DG, Moher D (2010) CONSORT 2010 statement: updated guidelines for reporting parallel group randomized trials. Ann Int Med 152(11):726-732

13. Gensini GGMD (1975) Chapter x. The pathological anatomy of the coronary arteries of man. Coronary arteriography. Futura Publishing Co, Mount Kisco, pp 271-274

14. Ringqvist I, Fisher LD, Mock MI (1983) C.H.A.E.L., Davis, K.B., Wedel, H.A.N.S., Chaitman, B.R., \& Kaiser, G.C. Prognostic value of angiographic indices of coronary artery disease from the Coronary Artery Surgery Study (CASS). J Clin Invest 71(6):1854-1866

15. Dodge JR, Brown BG, Bolson EL et al (1992) Lumen diameter of normal human coronary arteries influence of age, sex, anatomic variation and left ventricular hypertrophy or dilation. Circulation 86:232-246

16. Mosseri M, Nahir M, Rozenman Y, Lotan C, Admon D, Raz I, Gotsman MS (1998) Diffuse narrowing of coronary arteries in diabetic patients: the earliest phase of coronary artery disease. Cardiology 89(2):103-110

17. Honing ML, Morrison PJ, Banaga JD et al (1998) Nitric oxide availability in diabetes mellitus. Diabetes Metab Rev 14:241-249

18. Balkau B (1999) Comment on the provisional report from the WHO consultation. European Group for the Study of Insulin Resistance (EGIR). Diabet Med 16:442-443

19. Mehrota R, Pandy AS, Chaudhary A (2010) Lipids. Health Dis 8:29

20. Grundy SM, Cleeman JI, Daniels SR et al (2005) Diagnosis and management of the metabolic syndrome: an American Heart Association/National Heart, Lung, and Blood Institute scientific statement. Circulation 112:2735-2752

21. Naruse K, Rask-Madsen C, Takahara N, Ha SW, Suzuma K, Way KJ, Zhang J (2006) Activation of vascular protein kinase C- $\beta$ inhibits Akt-dependent endothelial nitric oxide synthase function in obesity-associated insulin resistance. Diabetes 55(3):691-698 
22. Nishikawa T, Edelstein D, Du XL, Yamagishi SI, Matsumura T, Kaneda Y, Giardino I (2000) Normalizing mitochondrial superoxide production blocks three pathways of hyperglycaemic damage. Nature 404(6779):787-790

23. Piga R, Naito Y, Kokura S, Handa O, Yoshikawa T (2007) Short-term high glucose exposure induces monocyte-endothelial cells adhesion and transmigration by increasing VCAM-1 and MCP-1 expression in human aortic endothelial cells. Atherosclerosis 193(2):328-334

24. Feener EP, King GL (2001) Endothelial dysfunction in diabetes mellitus: role in cardiovascular disease. Heart Fail Monit 1:74-82

25. Mazzone T, Chait A, Plutzky J (2008) Cardiovascular disease risk in type 2 diabetes mellitus: insights from mechanistic studies. Lancet 371(9626):18001809

26. Yan SD, Schmidt AM, Anderson GM, Zhang J, Brett J, Zou YS, Stern D (1994) Enhanced cellular oxidant stress by the interaction of advanced glycation end products with their receptors/binding proteins. J Biol Chem 269(13): 9889-9897

27. Schianca GPC, Rossi A, Sainaghi PP, Maduli E, Bartoli E (2003) The significance of impaired fasting glucose versus impaired glucose tolerance: importance of insulin secretion and resistance. Diabetes Care 26(5):13331337

28. Haffner SM, Stern MP, Hazuda HP, Mitchell BD, Patterson JK (1990) Cardiovascular risk factors in confirmed prediabetic individuals: does the clock for coronary heart disease start ticking before the onset of clinical diabetes? Jama 263(21):2893-2898

29. Kadi H, Ceyhan K, Karayakali M, Celik A, Ozturk A, Koc F, Onalan O (2011) Effects of prediabetes on coronary collateral circulation in patients with coronary artery disease. Coron Artery Dis 22(4):233-237

30. Kendall DM, Cuddihy RM, Bergenstal RM (2009) Clinical application of incretin-based therapy: therapeutic potential, patient selection and clinical use. Eur J Int Med 20:S329-S339

31. Matthews DR, Cull CA, Stratton IM, Holman RR, Turner RC (1998) UKPDS 26: sulphonylurea failure in non-insulin-dependent diabetic patients over six years. Diabet Med 15(4):297-303

32. Kahn SE (2003) The relative contributions of insulin resistance and beta-cell dysfunction to the pathophysiology of type 2 diabetes. Diabetologia 46(1): 3-19

33. Salminen M, Kuoppamäki M, Vahlberg T, Räihä I, Irjala K, Kivelä SL (2010) The metabolic syndrome defined by modified International Diabetes Federation criteria and mortality: a 9-year follow-up of the aged in Finland. Diabetes Metab 36(6):437-442

34. Srinivasan MP, Kamath PK, Manjrekar PA et al (2013) Correlation of severity of coronary artery disease with insulin resistance. N Am J Med Sci 5(10):611

35. Stout RW (1979) Diabetes and atherosclerosis — the role of insulin. Diabetologia 16(3):141-150

36. Nurkalem Z, Hasdemir H, Ergelen M et al (2010) Relationship between glucose tolerance and severity of coronary artery disease using the Gensini. Angiology 61:751

37. Monteiro CMDC, Pinheiro LF, Izar MC, Barros et al (2010) Highly sensitive Creactive protein and male gender are independently related to the severity of coronary disease in patients with metabolic syndrome and an acute coronary event. Braz J Med Biol Res 43(3):297-302

\section{Publisher's Note}

Springer Nature remains neutral with regard to jurisdictional claims in published maps and institutional affiliations.

\section{Submit your manuscript to a SpringerOpen ${ }^{\circ}$ journal and benefit from:}

- Convenient online submission

- Rigorous peer review

- Open access: articles freely available online

- High visibility within the field

- Retaining the copyright to your article

Submit your next manuscript at $\boldsymbol{\nabla}$ springeropen.com 